\title{
Hedges in Students' Reflective Feedback: Evidence from an Online Class during COVID-19 Outbreak
}

\author{
Arina Isti'anah,,$^{1 *}$ Anindita Dewangga Puri ${ }^{2}$ \\ Universitas Sanata Dharma ${ }^{12}$ \\ ${ }^{*}$ Corresponding Author \\ Email: arina@usd.ac.id \\ DOI: http://dx.doi.org/10.18326/jopr.v3i2.86-96
}

Copyright (C) The Author (s)

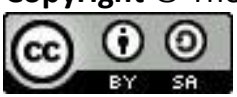

This work is licensed under a Creative Commons Attribution-ShareAlike 4.0 International License.

How to Cite: Isti'anah, A., \& Puri, A. (2021). Hedges in Students' Reflective Feedback: Evidence from an Online Class during COVID-19 Outbreak. Journal of Pragmatics Research, 3(2), 86-96. doi:https://doi.org/10.18326/jopr.v3i2.86-96

\begin{abstract}
Submission
Track:

Received:

19-03-2021

Final Revision:

10-05-2021

Available online:

01-10-2021

Corresponding

Author:

Arina Isti'anah arina@usd.ac.id

ABSTRACT

Scholars have observed hedges in academic writing, yet the examination of hedges in students' reflective feedback is scarcely found. During the Covid-19 pandemic, both teachers and students face difficulty engaging themselves in online classes. To figure out how students show their attitude, among others, is through reflective feedback. One of the languages features pivotal in reflective feedback is 'hedge', a pragmatic feature representing a speaker's tentativeness and possibility in communication (Lakoff, 1973). This paper addresses two questions: (1) what types of hedges are used in the students' reflective feedback in online class during the covid-19 outbreak? and (2) what are the functions of the hedges? This paper took 151 samples of students' reflective feedback in the introduction to English linguistics class at Sanata Dharma University to answer those problems. Findings reveal that the students dominantly used modal auxiliaries and epistemic adverbs as the types of hedges as a politeness technique to convey their anxiety and hesitation during an online class.

Keywords: hedges, reflective feedback, online class
\end{abstract}

\section{INTRODUCTION}

Hedges are commonly found in both spoken and written communication. Not only are hedges used to show a speaker's confidence in communication, hedges are also examined to figure out a speaker's attitude or possibility in communication. Lakoff introduces the term "hedges" as "words whose meaning implicitly involves fuzziness-words whose job is to make things fuzzier or less fuzzy" (Lakoff, 1973). Takimoto (2015) postulates that hedges are textual, linguistic strategies for communicative purposes (Takimoto, 2015). Hyland (2005) argues that hedges reduce the strength 
of an expression by expressing tentativeness and possibility (Hyland, 2005). Hedges also indicate a lack of commitment to the truth value of an accompanying proposition or a desire not to express that commitment categorically (Hyland, 1998). Hedges are based on the writer's plausible reasoning rather than specific knowledge that indicates the degree of commitment (Hyland, 2005). Therefore, hedges can be found in the form of some linguistic categories, such as modality, adjectives, adverbs, verbs, and nouns.

In addition, people tend to use hedges to show their certainty of their claims. The writer's interpretation in a statement can also be implied using hedges (Hyland, 2005). Hyland (2005) proposes three major categories of hedges: modal auxiliaries such as may, would, and could; epistemic adverbs and adjectives such as possibly, about, and perhaps; and epistemic lexical verbs such as indicate, suggest, and seem. Further, Hyland (2005) proposes three main functions of hedges. The first function is to reduce the force of statements, seen from the lexicon like fairly, partly, and at least. The second function is to make statements indefinite seen from the lexicon like usually and sometimes. The third function of hedges is to decrease the responsibility for the truth, seen from the lexicon such as perhaps, might, and seem.

Hyland, furthermore, maps the functions of hedges seen from the word categories. The employment of verbs as hedges function to avoid the speakers' being too assertive and to report ideas. On the other hand, the use of adverbs is to show the degree of probability, avoid the exact frequency of action or event in time or avoid the exact figure, and reduce the force of the verb. When adjectives are used as hedges, the speakers aim to show a tentative representation of frequency, avoid the commitment to exact numbers, and draw attention to the approximate nature of the information presented (Hyland, 1998). Munir (2013) further proposed that hedges also convey possibility, signal distance, and tone-down statements (Hooi \& Shuib, 2014).

Scholars have observed hedges in research articles, theses, and academic writings in EFL context (Kartikasari, 2019; Nguyen Thi Thuy, 2018; Rezaie \& Taki, 2014; Salichah, Irawati, \& Basthomi, 2015; Sanjaya, Sitawati, \& Suciani, 2015; Tabatabaei \& Ramzi, 2015). Previous research has figured out that hedges are employed to reduce the risk of opposition, mitigate the certainty of their claims and views, be more interpretative, be precise, and be polite. Hedges are also examined to figure out men's and women's language features (Azizah, 2021; Tabatabaei \& Ramzi, 2015). The research found that men and women have different strategies of hedging in writing. Despite the rich examination of hedges in various academic writing, the examination of hedges in students' reflective feedback is rarely found. This paper, thus, intends to fill the gap by discussing how hedges are used in the students' reflective feedback in online class during the covid-19 pandemic. This paper argues that hedges in students' reflective feedback function differently from those in research articles since reflective feedback has a more personal engagement to the readers or the teachers.

Reflection in the learning process is an essential factor in the acquisition of self-direction and self-regulation (Veine et al., 2020). By reflection, students are encouraged to become aware of their 
learning strategies, including what they have learned, their efforts, and what barriers they have faced during learning. Handerson et al. (2018) describe feedback as "a process in which learners make sense of information about their performance and use it to enhance the quality of their work or learning strategies" (Ducasse \& Hill, 2019). During the covid-19 outbreak, students are forced to join online classes that encourage them to be self-regulated learners. To figure out how they experience the learning process, reflective feedback becomes essential to involve since it supports and stimulates students to reflect on the learning processes and achievements (Veine et al., 2020).

In the context of Sanata Dharma University, the online classes have been conducted since March 2020. The lecturers had to switch their traditional into online courses. The new semester that began in August 2020 was more prepared. The university provided workshops and online platforms for teaching. During two weeks, the lecturers learned how to maximize the use of LMS and Zoom cloud meetings. LMS is a web-based software platform used as classroom management that provides an interactive online environment and automates the administration, organization, delivery, and reporting of educational content and learning outcomes (Turnbull, Chugh, \& Luck, 2020). The obligatory platform to use was Moodle accessed on belajar.usd.ac.id. Moodle stands for Modular Object-Oriented Dynamic Learning Environment that is integrated into university websites (Jokhan, Sharma, \& Singh, 2019). Moodle is responsive, accessible, and easy to navigate by laptops or mobile phones; with these well-prepared platforms and skills, the university expected better learning outcomes of the online classes. To figure out the students' attitude in online class during the covid19 pandemic, lecturers required students to give their reflective feedback after class. The students' feedback is pivotal for class evaluation.

Based on the background explained previously, this paper addresses two problems:

1. What categories of hedges are found in the students' reflective feedback in online class during the Covid-19 pandemic?

2. What are the functions of the hedges?

This paper intends to examine how students show their attitude in online classes from the reflective feedback they submit. To be particular, this paper aims to find their commitment in online classes seen from the use of hedges in their reflection.

\section{RESEARCH METHOD}

This paper employed a pragmatic approach, particularly by examining how students use hedges in their reflective feedback. There were 151 samples of reflective feedback by the students from the third semester at the English Letters Department, Sanata Dharma University. The participants were enrolled in the Introduction to English Linguistics class, the obligatory course for the students before taking linguistics classes in the upcoming semester. The students must pass the course with a $\mathrm{C}$ as the minimum grade. Nevertheless, they must retake the course in the following year. The class was conducted entirely online using LMS as the main platform to use in which the 
teacher uploaded materials and learning sources. The course had four credits, conducted twice a week. The teacher used a Zoom cloud meeting once a week, conducted around 40 to 60 minutes. Before class, the students were required to read the uploaded materials and complete the given worksheets. For the material and worksheet clarification, the teacher used the Zoom meeting. This activity was repeated throughout the semester. At the end of a topic, the students were required to give reflective feedback in LMS.

Among others, this paper took some questions in the reflective feedback:

1. After reading and completing the materials of this topic, please narrate your feedback on the learning process and the things you learned.

2. How important is it to know the production of English consonants and vowels? How will this material help you deal with your English ability, particularly the spoken one?

3. What efforts have you made to comprehend the materials on phonology?

4. What difficulties/ barriers did you face during the learning?

5. Please describe the things you have enjoyed in learning linguistics?

This paper examined the students' reflective feedback by observing lexical choices that express hedges to analyze the data. To categorize types of hedges, this paper adapts Hyland's model of hedges.

\section{RESULTS \& DISCUSSION}

The data used in this paper involve 151 of the students' reflections given in the first two weeks of the semester. From the total data, there were a total of 11,121 words. The following parts discuss the categories of hedges and their functions in the students' reflective feedback.

\section{Categories of Hedges in Students' Reflective Feedback}

There are found 151 expressions that are included as hedges. The table below summarizes the categories of hedges found in the students' reflective feedback.

Table 1. The categories of hedges in students' reflective feedback

\begin{tabular}{clccc}
\hline No. & Types of Hedges & Frequency & $\%$ & examples \\
1 & Epistemic adverbs & 59 & 39 & still, personally, overall, never really, a little bit, \\
& & & & kind of, rather \\
2 & Modal auxiliaries & 59 & 39 & maybe, can, unable, could, would \\
3 & Epistemic lexical verbs & 29 & 19 & think, feel like, become, \\
4 & Epistemic adjectives & 4 & 3 & be like, pretty, quite \\
& Total & 151 & 100 & \\
\hline
\end{tabular}

The table above reveals that there are three categories of hedges found in the students' reflective feedback. There is a total of 151 hedges used, dominated by epistemic adverbs and modal auxiliaries.

Epistemic adverbs are the category of hedges primarily found in the students' reflective feedback. Below are some examples.

1) I can understand the materials, but I haven't fully remembered it. 
2) With this topic I know a lot about the origin and formation of sounds and the actual way of pronouncing it, but I was still a little confused and tried to understand more deeply. Learning about new things is very interesting especially if learning offline, I think it will be fun.

3) We know before, even we can learn from animal, where there is signal language. I personally found that language is interesting.

In the examples displayed above, hedges are involved in the students' reflective feedback in the form of adverbs. In feedback (1), the student used the adverb entirely to modify the verb remember. Here, the student is not sure of what s/he said related to the materials they learned. Unlike traditional classes that enable students to comprehend the materials under the teacher's supervision, the online class requires students' self-regulated learning. Similarly, feedback (2) used the adverb little to modify the adjective confused. Both hedges refer to the students' weaknesses and barriers during an online class. Using adverbs, feedback (3) involves hedges to show the student's impression of the material. Though the adverbs modify different verbs, feedbacks (1) to (3) contain hedges. Students did not explicitly claim their experience and impression in online learning.

Other than epistemic adverbs, students used modal auxiliaries to show their commitment in the online class. There are some modal auxiliaries used: can, unable, maybe. Below are some examples of students' reflective feedback with modal auxiliaries.

4) From this material I gained new knowledge, which is about systems and patterns of speech sounds in English. At first, I was confused about this material (because it was completely new to me), and felt that it was quite difficult. However, I tried to understand the material (read and heard the audio PPT again, reread the discussion on WhatsApp group, and watched the Zoom meeting record on YouTube again), and can gradually understand the material in phonology.

5) I learned the materials before the class and I reviewed it after the class. The only one struggle for me is I can't understand it clearly especially if I had the discussion on WhatsApp. I enjoy this topic because I gained valuable knowledge.

6) My struggle is when the class is via WhatsApp group, because I can understand more when the class is via Zoom meeting.

Having a different background also makes the students have different ways of understanding the materials. The feedback (4), showed that the student gains new knowledge although at the first time he or she was confused. The modal auxiliary can is used as the result of his or her commitment during the online class. By reading and hearing the material, rereading the discussion on WhatsApp group, and watching the zoom meeting record on YouTube, the student showed the commitment to learning the new materials. Feedback (5) reveals the struggle from a student in understanding the discussion via the WhatsApp group. Although he or she learned the materials before and after the class, this student still did not understand the materials clearly, seen by using a negative form of modal auxiliary can't. Besides, feedback (6) also showed the student's commitment during the online class. It can be seen from the use of modal auxiliary, which explains that the student really understood the material if given directly via zoom meeting.

The next category of hedges is the use of lexical verbs. Unfortunately, there are only two verbs used showing hedges as seen below. 
7) I think the material is delivered more clearly when the class is held through a video conference.

8) Difficulties I have faced is maybe because this is an online class and there were a lot of WhatsApp group discussions, I feel like it was hard to understand the materials.

9) I think, these materials are difficult to learn, but it is very interesting \& it is answering my curiosity about how words are spoken.

From the three examples above, the use of lexical verbs in hedges expressions can be seen from the words think and feel like. In feedback (7) and (9), the students use the lexical verb to show their doubts or uncertainty in understanding the materials given in the Introduction to English Linguistics class. Moreover, the word feel like in feedback (8) also indicates the uncertainty of the student about the materials of the subject. Those lexical verbs signal students' hesitation in the class. The students tried to figure out the best strategies to comprehend the materials. The students' choice of video conference via Zoom indicated that they needed the teacher's presence and explanation of the materials. The discussion conducted via WhatsApp Group was not sufficient to enhance their understanding. EFL learners with low English proficiency tend to hinder their engagement in an online class (Cheng \& Ding, 2021).

The final form of hedges found in the students' reflective feedback is an epistemic adjective, though only found in 4 clauses. Below are the examples of epistemic adjectives:

10) Well, I don't think it's necessary to list down what I have learnt because that is quite a lot of theories. But, the essence of those new things is quite the same under the concept that language even has its own ideal formation and specific characters.

11) I feel the productive online learning in this course, the material is pretty uncommon but followable.

The students' epistemic adjectives are quite and pretty used in their reflective feedback from the data above. For example, in feedback (10), the adjective is used to modify the noun phrase many theories. However, the students did not emphasize the enormous number of materials to learn since $\mathrm{h} /$ she used the hedges quite. Similarly, the student was also unsure of what s/he feels of the material by including the adjective pretty to modify the material.

The domination of epistemic adverbs and modal auxiliaries in the students' reflective feedback shows that hedges are used to modify the verbs. The students are not sure of their actions and feelings. In following the online learning, students were doubtful whether the lecturer expected their understanding. It signals the students' anxiety since they are worried about the grade they would get at the end of the semester. Students' feelings about the materials and methods applied are also narrated by involving hedges. Even though the students have faced online learning for almost a year, they were still anxious about their understanding and feelings in online learning. This situation is in line with research in China about students' anxiety during online classes (Rizun \& Strzelecki, 2020). 


\section{Functions of Hedges in Students' Reflective Feedback}

The hedges found in the students' reflective feedback have some functions. They are to decrease the responsibility for the truth, reduce the force of statements, and make statements indefinite. The table below summarizes the functions of hedges in students' reflective feedback.

Table 2. The functions of hedges in students' reflective feedback

\begin{tabular}{cccc}
\hline No. & \multicolumn{1}{c}{ Types of Hedges } & Frequency & \% \\
1 & $\begin{array}{l}\text { To decrease the } \\
\text { responsibility for the } \\
\text { truth }\end{array}$ & 55 \\
2 & $\begin{array}{l}\text { To reduce the force of } \\
\text { statements } \\
\text { To make statements } \\
\text { indefinite } \\
\text { Total }\end{array}$ & 7 & 50 \\
\hline
\end{tabular}

The table above shows that the most dominant function of hedges in students' reflective feedback is to decrease the responsibility for the truth, shown in 83 clauses, or $55 \%$ of the data. The following function of hedges in the feedback is to reduce the force of statements, presented in 61 clauses, or $40 \%$ of the data. The last function of hedges is to make statements indefinite, found in 7 clauses or $5 \%$ of the total data.

The covid-19 outbreak has forced students to switch their learning strategies. Students have to figure out a combination of activities students use to achieve their learning goals (Cheng \& Ding, 2021). Teachers expect students to become self-regulated learners, yet not all students are aware of the necessity of becoming independent learners. The struggle becomes real when students face anxiety during their online learning. University students are mentioned to have a higher level of anxiety after the covid-19 outbreak, surveyed with 3,800 respondents in China (Rizun \& Strzelecki, 2020). Students are worried about their grades since they are not sure whether they can follow the online class well. One of the problems that are often found is an unstable internet connection. Some students mention that they have to use a cell phone to follow the learning process since they do not have a laptop, or the laptop is used by another family member having online learning.

Concerning the online learning process, this paper examined the students' feedback. One of the linguistic features prominent to show the students' attitudes are hedges. Table 2 displays three functions of hedges based on Hyland's theory. The most dominating function of hedges in the students' feedback is to decrease the responsibility for the truth. Relating it to the students' experience during online class, the students show uncertainty about an assertion's truth. Below are the examples.

12) Topic 2 helps me to understand words more than before and also encourage me to speak clearly. Besides that, personally even though it is kind of complicated, but our topic about phonetics is very fun to learn.

13) Despite my best efforts, this topic is still very difficult for me to fully learn and apply. It is very hard for me to memorize all the classifications and phonetic symbols, but my learning is increasing with every class period taken. 
Both feedback (12) and (13) above are categorized as epistemic adverbs that function to decrease the responsibility for the truth. The student needed more time to process the materials. The students were not sure of their understanding of the materials. Unlike a traditional classroom that enables them to directly have dialogue and discussion with the lecturer and other students, online learning forced them to learn the materials independently.

In feedback (12), the students decrease the responsibility of their utterance. Instead of saying that the material is complicated, the student used kind of as a politeness strategy (Ahmed \& Maros, 2017). Since the feedback is addressed to the lecturer, the student did not want to get any negative feedback from the reader (Vebriyanto, Mujiyanto, \& Fitriati, 2019). Similarly, the student was reluctant to assert the difficulty of the materials. Instead of using very difficult reflective feedback, the student chose to use hedges still to decrease the responsibility of the truth. Students did not want to show their pessimism in online learning. However, during the discussion in zoom meetings, there were only a few students who asked questions related to the materials given. Most of them did not address questions for clarification, even though they mentioned difficulty understanding the materials in the reflective feedback. It indicates that the student's learning strategy is surface learning, meaning that the students simply scrapped the surface of the learning materials without processing it deeply (Cheng \& Ding, 2021).

This paper argues that students are not confident with their attitude in an online class. Students try to choose a platform that they feel convenient, but they also support the teacher's using other platforms in the class. Below are examples of students' feedback.

14) I'd rather choose the Zoom meetings. I enjoyed the new knowledge and explanations that you have given during class. It made me realize that you have to work hard on learning English.

15) I do try to understand the material and I have understood it in my own way, but when I answered the quiz, it kept making me confused every time because when I thought that I at least answered most of the questions correctly, I still received a low score. I'm confused about what and which questions I got wrong. Despite all the confusion, I do really quite enjoy this class and the material being taught.

According to the feedback (14), hedges had a function to reduce the force of the statement. The student uses the word rather to show his or her attitude to sound more polite. It expresses that the student is more confident to use the zoom meeting than another online platform during this online class. Due to the pandemic, teachers and students are required to be more creative in using the online platforms, and it makes both of them have to adapt to it. However, not all online platforms are suitable for use during teaching-learning activities. The student chose the adverb rather to avoid being assertive in giving his or her opinion, and it will make their sentence more polite.

Meanwhile, the hedges in feedback (15) indicated that the student used a more polite word to express her/his feeling during this online class. The student was confused about her/his feeling since the feedback also contains a booster really. Here, students faced engagement in online learning and anxiety about the score they got in the assignments or quizzes. Students' lack of engagement in the 
online class happens due to the limited discussion during synchronous learning (Hill \& Fitzgerald, 2020). The lecturer has motivated students to prepare their readings and worksheet completion to discuss synchronously in zoom meetings, but only a few students prepared themselves. The students' readiness to become self-regulated learners is central to support the success of online learning.

The last function of hedges found in students' reflective feedback is to make statements indefinite. Below are the examples of that function:

16) My effort is to study more of this material carefully. Sometimes I am still not focused, when I read the material. I really enjoy every moment and of course for the new material.

17) I think sometimes it is quite difficult for me to comprehend the examples of co-articulation effects. Even when I already looking up for the examples to differentiate them, I always have to think harder whenever I look into other words. I cannot conclude which co-articulation that the words use immediately.

According to the data above, the adverbs sometimes and always in feedback (16) and (17) function to make the statement indefinite. The Covid-19 outbreak forces the students to be independent learners so that they are expected to understand the materials that the teacher has provided through the online platform. To understand the materials, the students need extra effort in this online class rather than offline class. As seen in feedback (16), the student used the word sometimes to show his or her uncertain feeling, whether s/he can focus or not when s/he reads the material. It makes the statement indefinite. Although the student shows uncertainty during her or his effort to understand the materials, the student also shows optimism during the course since the feedback contains a booster really. However, boosters appear very low in the data, so this research did not conclude that students are optimistic about following the online class. Feedback (17) indicates that the student faced difficulties understanding one of the materials given in the learning process. The word always shows the frequency or how often something happens; in this context, s/he often had to think harder whenever s/he looked into other words for an indefinite period. The student also did not emphasize how big the difficulties that s/he faced by using the hedges quite to comprehend one of the materials given during this online class.

In spoken communication, hedges function to maintain smooth communication, make statements less offensive and make opinions more convincing (Ahmed \& Maros, 2017). In the reflective feedback, hedges are employed to show politeness and hesitation, and anxiety. The written communication has given students more chances to express what they feel and experience in an online class. However, hedges in reflective feedback also have a different form and function from in academic writing. While M.A. and Ph.D. theses by Persian writers are dominated by adjectives (Rezaie \& Taki, 2014), the present study found that epistemic adverb and modal auxiliary are the forms of hedges found the most. While hedges in academic writing are employed to become more assertive in writing (Rezaie \& Taki, 2014), hedges in reflective feedback are used to become less assertive and soften the statement to achieve politeness (Hasanah \& Wahyudi, 2015). Since the reflective feedback was addressed to the lecturer, the students were reluctant to express their experience strongly. This strategy is similar to hedges in undergraduate theses in Indonesia, which 
shows that hedges were employed to reduce the risk of opposition, as a politeness strategy, to obscure their authorial identity (Salichah et al., 2015).

\section{CONCLUSION}

Hedges are pragmatic features that show the speakers/ writers' attitude in expressing their proposition. In online class during the covid-19 outbreak, students face difficulty following the online learning even though the teacher was prepared with the materials and teaching methods/ strategies. From the reflective feedback collected from the students of Introduction to Linguistics, Sanata Dharma University, hedges are involved in epistemic adverbs, modal auxiliaries, lexical verbs, and epistemic adjectives. The students used epistemic adverbs and modal auxiliaries the most compared to the other forms of hedges. Findings show that students involved hedges in their feedback to convey their anxiety and hesitation in following the online learning. However, they present their feelings and experiences using hedges to achieve politeness. Instead of being assertive that they found difficult and felt anxious to follow the class, students tried to respect the teacher's effort to prepare the online teaching-learning process. This paper suggests future researches compare the use of hedges in different gender using similar data, reflective feedback.

\section{REFERENCES}

Ahmed, W. K., \& Maros, M. (2017). Using Hedges as Relational Work by Arab EFL Students in Student-Supervisor Consultations. GEMA Online ${ }^{\circledR}$ Journal of Language Studies, 17(1), 89105. https://doi.org/10.17576/gema-2017-1701-06

Azizah, D. N. (2021). Hedges Function in Masculine and Feminine Feature's Language: A Pragmatics Analysis. Journal of Pragmatics Research, 3(1), 59-69. https://doi.org/10.18326/jopr.v3i1.59-69

Cheng, P., \& Ding, R. (2021). The effect of online review exercises on student course engagement and learning performance: A case study of an introductory financial accounting course at an international joint venture university. Journal of Accounting Education, 54, 100699. https://doi.org/10.1016/j.jaccedu.2020.100699

Ducasse, A. M., \& Hill, K. (2019). Developing Student Feedback Literacy Using Educational Technology and the Reflective Feedback Conversation. Practitioner Research in Higher Education, 12(1), 24-37.

Hasanah, U., \& Wahyudi, R. (2015). Meaning-making of hedges in the gossip column of The Jakarta Post. Humaniora, 27(2), 207-216.

Hill, K., \& Fitzgerald, R. (2020). Student perspectives on the impact of COVID-19 on learning. AISHE, 12(2), 1-9.

Hooi, C. M., \& Shuib, M. (2014). An Analysis of Hedging Devices in Complaint Business Letters. GEMA Online Journal of Language Studies, 14(03), 123-142. https://doi.org/10.17576/GEMA-2014-1403-08

Hyland, K. (1998). Hedging in scientific research articles. Amsterdam: John Benjamins. 
Hyland, K. (2005). Metadiscourse: Exploring interaction in writing. London; New York: Continuum.

Jokhan, A., Sharma, B., \& Singh, S. (2019). Early warning system as a predictor for student performance in higher education blended courses. Studies in Higher Education, 44(11), 1900-1911. https://doi.org/10.1080/03075079.2018.1466872

Kartikasari, I. (2019). Comparison of Hedging Devices in Published Research Articles by Indonesian and English Native Writers: A Corpus Based Study. Jurnal Pendidikan Humaniora, 7(2), 38-45.

Lakoff, G. (1973). A Study in Meaning Criteria and the Logic of Fuzzy Concepts. Journal of Philosophical Logic, 2(4), 458-508.

Nguyen Thi Thuy, T. (2018). A Corpus-Based Study on Cross-Cultural Divergence in the Use of Hedges in Academic Research Articles Written by Vietnamese and Native English-Speaking Authors. Social Sciences, 7(4), 1-13. https://doi.org/10.3390/socsci7040070

Rezaie, M., \& Taki, S. (2014). Hedging Expressions in English and Persian MA and PhD Theses: The Case of Iranian Learners. Mediterranean Journal of Social Sciences, 5(20), 2339-2349. https://doi.org/10.5901/mjss.2014.v5n20p2339

Rizun, M., \& Strzelecki, A. (2020). Students' Acceptance of the COVID-19 Impact on Shifting Higher Education to Distance Learning in Poland. International Journal of Environmental Research and Public Health, 17(18), 6468. https://doi.org/10.3390/ijerph17186468

Salichah, I., Irawati, E., \& Basthomi, Y. (2015). Hedges and Boosters in Undergraduate Students' Research Articles. Jurnal Pendidikan Humaniora, 3(2), 154-160.

Sanjaya, I. N. S., Sitawati, A. A. R., \& Suciani, N. K. (2015). Comparing hedges used by English and Indonesian scholars in piblished research articles: A corpus-based study. TEFLIN Journal - A Publication on the Teaching and Learning of English, 26(2), 209-227. https://doi.org/10.15639/teflinjournal.v26i2/209-227

Tabatabaei, M. A., \& Ramzi, S. (2015). The Use of Hedges and Boosters in Monolingual and Bilingual EFL Learners' Academic Writings: The Case of Iranian Male and Female Postgraduate MA Articles. The Journal of Applied Linguistics, 6(12), 131-141.

Takimoto, M. (2015). A corpus-based analysis of hedges and boosters in English academic articles. Indonesian Journal of Applied Linguistics, 5(1), 95-105. https://doi.org/10.17509/ijal.v5i1.836

Turnbull, D., Chugh, R., \& Luck, J. (2020). Learning management systems: A review of the research methodology literature in Australia and China. International Journal of Research \& Method in Education, 1-15. https://doi.org/10.1080/1743727X.2020.1737002

Vebriyanto, D. A., Mujiyanto, J., \& Fitriati, S. W. (2019). Types and Functions of Hedges and Boosters in Graduate Students' Research Articles. English Education Journal, 9(4), 565574.

Veine, S., Anderson, M. K., Andersen, N. H., Espenes, T. C., Søyland, T. B., Wallin, P., \& Reams, J. (2020). Reflection as a core student learning activity in higher education-Insights from nearly two decades of academic development. International Journal for Academic Development, 25(2), 147-161. https://doi.org/10.1080/1360144X.2019.1659797 